\title{
Relationship of degree of anemia as direct or indirect causes of heart failure and its impact on maternal and fetal outcome
}

\author{
Neena Gupta ${ }^{1}$, Sachidanand Gupta ${ }^{2}$, Arti Lalchandani ${ }^{3}$, \\ Renu Gupta ${ }^{1}$, Seema Diwedi ${ }^{4}$, Jyotsna Singh $^{1 *}$
}

\begin{abstract}
${ }^{1}$ Department of Obstetrics \& Gynecology, GSVM Medical College, Kanpur, Uttar Pradesh, India
${ }^{2}$ Department of Anesthesia, Rama Medical College, Kanpur, Uttar Pradesh, India

${ }^{3}$ Department of Medicine, GSVM Medical College, Kanpur, Uttar Pradesh, India

${ }^{4}$ Department of Pediatrics, GSVM Medical College, Kanpur, Uttar Pradesh, India
\end{abstract}

Received: 11 September 2014

Accepted: 10 October 2014

\section{*Correspondence:}

Dr. Jyotsna Singh,

E-mail: jyotsna.0805@gmail.com

Copyright: ( $)$ the author(s), publisher and licensee Medip Academy. This is an open-access article distributed under the terms of the Creative Commons Attribution Non-Commercial License, which permits unrestricted non-commercial use, distribution, and reproduction in any medium, provided the original work is properly cited.

\begin{abstract}
Background: Objective of current study was to determine the impact of anemia as cause of heart failure in pregnancy and its associated maternal and fetal outcome.

Methods: It was a prospective study conducted in department of obstetrics and gynecology GSVM medical college, Kanpur, from January 2012 to august 2013 with total number of subjects being 6800. All maternal and fetal records were reviewed.

Results: Total number of antenatal patients admitted to our hospital during 20 month duration were 6800, out of which $48(0.17 \%)$ had heart failure. $47.91 \%$ patients among them had severe anemia as direct cause of heart failure, whereas anemia was associated as indirect cause of heart failure in $52.08 \%$ of patients. Poor maternal and fetal outcome were observed in patient with increasing severity of anemia.

Conclusions: With increase in degree of anemia susceptibility to heart failure increases and it was observed that there was increased incidence of adverse maternal and neonatal outcome in severe anemia when compared to mild and moderate anemia.
\end{abstract}

Keywords: Anemia, Heart failure, Maternal and Neonatal outcome

\section{INTRODUCTION}

Anemia is the most common nutritional deficiency disorder in the world. WHO has estimated that prevalence of anemia in developed and developing countries in pregnant women is 14 percent and 51 percent respectively and 65-75 percent in India.

Prevalence of anemia in India is among the highest in the world. Even among higher income educated segments of population about 50 per cent of children, adolescent girls and pregnant women are anemic. Inadequate dietary iron, folate intake due to low vegetable consumption, perhaps low $\mathrm{B}_{12}$ intake and poor bioavailability of dietary iron from the fibre, phytate rich Indian diets are the major factors responsible for high prevalence of anemia. Increased requirement of iron during growth and pregnancy and chronic blood loss contribute to higher prevalence in specific groups. In India, anemia is directly or indirectly responsible for 40 percent of maternal deaths. There is 8 to 10 -fold increase in MMR when the hemoglobin falls below $5 \mathrm{~g} / \mathrm{dl}$. Early detection and effective management of anemia in pregnancy can contribute substantially to reduction in maternal mortality. Maternal anemia is associated with poor intrauterine growth and increased risk of preterm births and low birth weight rates. This in turn results in higher 
perinatal morbidity and mortality, and higher infant mortality rate.

Three distinct stages of severe anemia have been recognized - compensated, decompensated, and that associated with circulatory failure. Cardiac decompensation usually occurs when Hemoglobin falls below $5.0 \mathrm{~g} / \mathrm{dl}$. The cardiac output is raised even at rest, the stroke volume is larger and the heart rate is increased. Palpitation and breathlessness even at rest are symptoms of these changes. These compensatory mechanisms are inadequate to deal with the decrease in Hemoglobin levels. Oxygen lack results in anaerobic metabolism and lactic acid accumulation occurs. Eventually circulatory failure occurs, further restricting work output. Untreated, it leads to pulmonary edema and death.

Anemia is known to cause CHF even in people with no underlying heart disease, and correction of the anemia with transfusions can correct the $\mathrm{CHF}$.

\section{METHODS}

The present study was conducted on pregnant female with gestational age between 37 to 42 weeks with heart failure, admitted to hospital UISEMH, Kanpur from January 2012 to August, 2013. We attended 6800 pregnant female admitted to hospital out of which 48 pregnant female had heart failure during pregnancy or in labor according to underlying etiology. They were classified as those with direct causes viz structural cardiac defect, pregnancy induced cardiac dysfunction in peripartum cardiomyopathy or indirect causes severe anemia, hypertensive disorder of pregnancy, sepsis and volume overload.

This was descriptive observational study. A detailed history was taken and distribution was made according to socio-economic status using Kuppuswamy classification. Further descriptive analysis was done in terms of age and parity. Patients were classified as booked or unbooked case. Proper evaluation of antenatal visits including cardiology follow-up was done.

History of known case of cardiac disease and time of its diagnosis, medical and surgical treatment taken, history of rheumatic failure in childhood, cardiac failure at any time and family history of rheumatic fever was taken. Detailed obstetrical history with special emphasis on antenatal complaint and previous issues and its antenatal period was elicited. A thorough obstetric examination was done. Besides routine antenatal investigation complete blood count and arterial blood gas analysis was done. Electrocardiogram, chest X-ray and echocardiography was done for cardiac evaluation.

Treatment was started in the view of heart failure. Those requiring ventilatory support was transferred to medicine intensive care unit or anesthesia Intensive care unit or pulmonary medicine Intensive care unit based on ventilator availability.

Maternal outcome in terms of survival and expiry was noted and categorized among those shifted to Intensive care unit for ventilator support and those not. Fetal outcome assessment was done as dead born or live issues. Live issues were further categorized among term, preterm and IUGR. Each etiology of heart failure during pregnancy and labor were studied for their maternal and fetal outcome.

\section{RESULTS}

Total number of antenatal patients admitted to our hospital during 20 month duration was 6800, out of which $48(0.17 \%)$ had heart failure. Table 1 denotes that majority of the patients belonged to age group between $20-24$ years $(62.50 \%)$, most of them were primigravida $41.67 \%$ and belonged to lower socio-economic status (58.33\%), none of the patient was booked. $23(47.91 \%)$ patient had severe anemia as direct cause of heart failure, whereas anemia was associated as indirect cause of heart failure in $25(52.08 \%)$ of patients (Table 2$)$.

Table 1: Sociodemographic data.

\begin{tabular}{|lll|}
\hline $\begin{array}{l}\text { Age group } \\
\text { (in years) }\end{array}$ & $\begin{array}{l}\text { No. of cases } \\
(\mathbf{n = 4 8})\end{array}$ & $\begin{array}{l}\text { Percentage } \\
(\%)\end{array}$ \\
\hline $15-19$ & 5 & $10.42 \%$ \\
\hline $20-24$ & 30 & $62.50 \%$ \\
\hline $25-29$ & 10 & $20.83 \%$ \\
\hline $30-34$ & 2 & $4.17 \%$ \\
\hline $35-39$ & 1 & $2.08 \%$ \\
\hline Parity & 20 & $41.67 \%$ \\
\hline P0 & 17 & $35.42 \%$ \\
\hline P1 & 8 & $16.67 \%$ \\
\hline P2 & 3 & $6.25 \%$ \\
\hline P3 or $>$ & - & - \\
\hline Socio-economic status & $41.67 \%$ \\
\hline Upper & 20 & $58.33 \%$ \\
\hline Middle & 28 & \\
\hline Lower & & $95.83 \%$ \\
\hline Booked /unbooked & $4.17 \%$ \\
\hline Unbooked No visit & 46 & - \\
\hline B3 visit & 2 & \\
\hline Booked $(\geq 3$ visit $)$ & - & \\
\hline
\end{tabular}

Table 2: Anemia as direct or indirect cause of heart failure.

\begin{tabular}{|c|c|c|c|c|}
\hline \multirow{3}{*}{$\begin{array}{l}\text { Degree of } \\
\text { anemia }\end{array}$} & \multicolumn{4}{|c|}{ Cause of heart failure } \\
\hline & \multicolumn{2}{|c|}{ Direct $(n=23)$} & \multicolumn{2}{|c|}{ Indirect $(n=25)$} \\
\hline & No. & Percentage $\%$ & No. & Percentage $\%$ \\
\hline Mild & - & & 4 & $16 \%$ \\
\hline Moderate & - & & 21 & $84 \%$ \\
\hline Severe & 23 & $100 \%$ & - & - \\
\hline
\end{tabular}


Association of degree of anemia with other causes of heart failure is shown in Table 3 , it depicts that severely anemic patients had more susceptibility for volume overload, chances of sepsis was increased with increase in degree of anemia and due to various environmental and nutritional factor hypertensive disorder was also associated with anemia. In our study $64.58 \%$ of patients with heart failure expired, only $35.41 \%$ survived. Those who survived suffered from various morbidities which were also directly associated with degree of anemia, like puerperal sepsis, post-partum hemorrhage, septicemia all of these are more common in patients having severe anemia (Table 4).

$41.67 \%$ of neonates of mother with heart failure were dead born, $31.25 \%$ were preterm and $18.75 \%$ had intrauterine growth restriction, incidence of these fetal outcomes were also studied in association with degree of anemia (Table 5).

The effect of degree of anemia on birth weight and perinatal mortality were also studied and it depicts that as degree of anemia increases perinatal mortality increases while birth weight decreases.

Table 3: Association of degree of anemia as indirect cause of heart failure.

\section{Other cause of heart failure}

\begin{tabular}{|lllll|}
\hline $\begin{array}{l}\text { Degree of } \\
\text { anemia }\end{array}$ & $\begin{array}{l}\text { Heart } \\
\text { disease } \\
(\mathbf{n = 2 5})\end{array}$ & $\begin{array}{l}\text { Hypertensive } \\
\text { disorder } \\
(\mathbf{n = 8})\end{array}$ & $\begin{array}{l}\text { Sepsis } \\
(\mathbf{n = 2})\end{array}$ & $\begin{array}{l}\text { Volume } \\
\text { overload } \\
(\mathbf{n = 2})\end{array}$ \\
\hline $\begin{array}{l}\text { Mild } \\
\text { anemia* }\end{array}$ & 2 & 2 & - & - \\
\hline $\begin{array}{l}\text { Moderate } \\
\text { anemia** }\end{array}$ & 18 & 2 & 1 & - \\
\hline $\begin{array}{l}\text { Severe } \\
\text { anemia*** }\end{array}$ & 5 & 4 & 1 & 2 \\
\hline
\end{tabular}

*Mild (9-11 gm\%)

**Moderate (7-9 gm\%)

*** Severe $(4-7 \mathrm{gm} \%)$

Table 4: Maternal outcome of antenatal patients with anemia as cause of heart failure.

\begin{tabular}{|lllll|}
\hline $\begin{array}{l}\text { Maternal } \\
\text { outcome }\end{array}$ & $\begin{array}{l}\text { No. of } \\
\text { patients }\end{array}$ & $\begin{array}{l}\text { Degree of anemial } \\
\text { Mild }\end{array}$ & Moderate & Severe \\
\hline Expired & 31 & 5 & 11 & 15 \\
\hline $\begin{array}{l}\text { Survived } \\
\text { without any } \\
\text { morbidity }\end{array}$ & 8 & 7 & 1 & - \\
\hline $\begin{array}{l}\text { Puerperal } \\
\text { sepsis }\end{array}$ & 3 & - & 1 & 2 \\
\hline Septicemia & 4 & 1 & 1 & 2 \\
\hline $\begin{array}{l}\text { Post-partum } \\
\text { hemorrhage }\end{array}$ & 2 & - & - & 2 \\
\hline
\end{tabular}

Table 5: Fetal outcome of antenatal patients with anemia as cause of heart failure.

\begin{tabular}{|lllll|}
\hline Fetal outcome & No. of & \multicolumn{2}{l|}{ Degree of anemia } \\
neonates & Mild & Moderate & Severe \\
\hline Dead born & 20 & 1 & 5 & 14 \\
\hline Preterm & 15 & 2 & 5 & 8 \\
\hline IUGR & 9 & 1 & 3 & 5 \\
\hline Low birth weight & 28 & 4 & 7 & 17 \\
\hline Term & 3 & 2 & 1 & - \\
\hline
\end{tabular}

\section{DISCUSSION}

At our centre the percentage of pregnant female with heart failure is $0.7 \%(48 / 6800)$. This incidence was in contrast to one previously reported by Patience Olayinka Akinwuri et al. in $2010,{ }^{1}$ which was $0.22 \%$. The above mentioned study was done in Nigeria from 2004-2010. We studied age-wise distribution and concluded that $62.50 \%$ were in age-group between 20-24 years and $77.09 \%$ were primigravida this was due to their early marriage, adolescent pregnancy, ignorance, nonavailability and or failure to utilize available medical facilities.

Our study revealed results which were compared with same study by Patience Olayinka Akinwuri et al. in $2010,{ }^{1}$ in which $50 \%$ were primigravida. Majority of patient in our study belonged to low socio-economic status $(58.33 \%)$ reflecting poor quality of antenatal and intranatal care being provided and lack of adequate facilities in such areas, which was one of the important factor responsible for maternal anemia and its associated maternal and fetal outcomes. Oli K et al. $2009,{ }^{2}$ study shows similar result.

Out of 48 all were unbooked case (patient who had taken no antenatal visit or $<3$ antenatal visit), only 2 cases had single visit with no cardiology work up.

$100 \%$ cases in our study with heart failure were anemic of different degree $(8.33 \%$ mild, $43.75 \%$ moderate, $47.91 \%$ severe) and thus anemia was either alone a direct cause of heart failure or an indirect cause because of associated disease. This was strikingly different from study done in Israel by Donald S et al 2002 in which only $50 \%$ of cases due to any etiology of heart failure had associated anemia. ${ }^{3} 47.91 \%$ of patient had severe anemia as direct cause of heart failure, because, anemia leads to an increased heart rate and stroke volume and in response to the increased workload heart undergoes "remodeling", marked by left ventricular hypertrophy and dilation. This eventually may lead to CHF with an increased mortality risk. Patient with severe anemia had increased risk of volume overload because when hemoglobin falls below 5 $\mathrm{gm} / \mathrm{dl}$ decompensation occurs and cardiac output is increased even at rest, stroke volume is large and heart rate is increased which finally leads to volume overload. Puerperal sepsis and septicemia was present mostly in patient with severe anemia due to immune depression and 
consequently cause an increase in morbidity, and this was significant in women with hemoglobin $<8 \mathrm{gm} / \mathrm{dl}$. Riffat Jaleel et al. 2008 study has demonstrated a causal relationship between severe anemia and various maternal and perinatal complications. ${ }^{4}$ In our study, when maternal outcome was compared, $64.6 \%(31 / 48)$ of the patient with heart failure expired because in our setting most of these were severely anemic $(47.91 \%)$ with hemoglobin usually $<5 \mathrm{gm} / \mathrm{dl}$ and PCV $<14$, a blood loss of even 200 $\mathrm{ml}$ in the third stage produces shock and death in these women, even today women in the remote rural areas in India reach to the hospital only at this late decompensated stage. Available data from India indicate that maternal morbidity rates are higher in women with $\mathrm{Hb}$ below 8.0 $\mathrm{g} / \mathrm{dl}$. Maternal mortality rates show a steep increase when maternal $\mathrm{Hb}$ levels fall below $5.0 \mathrm{~g} / \mathrm{dl}$, whereas above study showed single death due to decompensated heart failure. $35.41 \%$ (17/48) patient who survived develop puerperal sepsis, post-partum hemorrhage, septicemia which necessitates ICU care for these patients. Fetal outcome was also compared with study by Ren et al. (2007) which showed increased risk of low birth weight, pre-term and intrauterine growth restriction in patients with low first trimester hemoglobin concentration. ${ }^{5}$ Kidanto et al. (2009) reported increased incidence of preterm and intrauterine growth restriction with increased degree of severity of anemia, ${ }^{6}$ these results were comparable with our study in which most of the preterm ,intra-uterine growth restriction and dead born neonates were seen in patient with severe anemia. Fall in maternal hemoglobin $<8 \mathrm{gm} / \mathrm{dl}$ were associated with significant rise in perinatal mortality rate, fall in birth weight due to increase in prematurity rate and intrauterine growth restriction. Immune depression in anemia and consequent increased morbidity due to infection might be one of the factors responsible for low birth weight babies in anemic women.

\section{CONCLUSION}

Anemia is the most commonly associated co-morbid disease, and could be a direct or indirect cause of heart failure. Anemia mild and moderate group constituted indirect cause of heart failure in $25(52.08 \%)$ of cases. Severe anemia is direct etiology in 23(47.91\%) cases. Pregnant patient with any high risk for heart failure must have early diagnosis and managed by multidisciplinary approach at tertiary care centre with ventilator support. Preventable causes like anemia must be dealt vigorously. Those with structural heart disease must have preconceptional visit to cardiologist and those with severe degree of disease must be forbidden from getting pregnant before surgical correction. Maternal and fetal outcome will markedly be improved with early diagnosis and efficient management. Anemia is preventable cause of death by special emphasis on prior antenatal visit, early diagnosis and targeted treatment as birth preparedness, skilled management of severe grades of anemia detected late in pregnancy, through blood transfusion and parenteral iron therapy, so these became the hallmark of good obstetric practice and resulted in appreciable maternal and perinatal salvage rates in hospitals. Health education to improve the utilization of available facilities and improvement in the health care delivery system to cater to the needy, right at their doorsteps might thus go a long way in reducing adverse obstetric outcome associated with maternal anemia.

\section{ACKNOWLEDGEMENTS}

The contribution of every author was appreciable along with the institution where study was conducted and all authors extend their sincere thanks to the patients who gave their consent for the inclusion in the study.

\section{Funding: No funding sources Conflict of interest: None declared Ethical approval: Not required}

\section{REFERENCES}

1. Patience Olayinka Akinwusi, Adetunji Oladeni Adeniji, Oluseyi, Olaboyede Atanda. Hospital-based incidence of maternal heart failure during pregnancy in Nigeria. Int J General Med. 2013;6:201-7.

2. Oli K, Porteous J. Prevalence of RHD among school children in Addis Ababa. East Afr Med J. 1999 Nov;76(11):601-5.

3. Donald S. Silverberga, DovWexlerb, Adrian Iainaa. The importance of anemia and its correction in the management of severe congestive heart failure. Eur $\mathbf{J}$ Heart Failure. 2002;4:681-6.

4. Riffat Jallel, Ayesha Khan. Severe anemia and adverse pregnancy outcome. J Surg Pak (Int). 2008 Oct-Dec;13(4):147-50.

5. Ren A, Wang J, Ye RW, Li S, Liu JM, Li Z. Low first trimester hemoglobin and low birth weight, preterm birth and small for gestational age newborns. Int J Gynecol Obstet. 2007;98:124-8.

6. Kidanto HL, Morgen I, Lindmark G, Massawe S, Nystrom L. Risks for preterm delivery and low birth weight are independently increased by severity of maternal anemia. S Afr Med J. 2009;99(2):98-102.

DOI: $10.5455 / 2320-1770 . i j r \operatorname{cog} 20141220$

Cite this article as: Gupta N, Gupta S, Lalchandani A, Gupta R, Diwedi S, Singh J. Relationship of degree of anemia as direct or indirect causes of heart failure and its impact on maternal and fetal outcome. Int J Reprod Contracept Obstet Gynecol 2014;3:982-5. 